\title{
College experience of academically successful students with autism
}

\author{
Sara Drake \\ Correspondence: sara.drake@park.edu

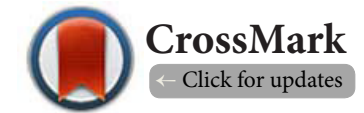

Park University, West Haven, UT 84401, USA.

\begin{abstract}
The number of individuals with autism attending college has grown with the increase of autism diagnosis. College students with autism graduate at a lower rate than their typically developed peers. Few studies have examined the phenomenon of college students with autism; instead the focus has been on projecting college performance based on high school challenges. This study explores the lived experiences of successful college students with autism. The participants, who had all completed a Bachelor's degree, described their college years and the lessons they learned. The superordinate themes were becoming self-aware, love of college, and exploring alternate means to socialize.
\end{abstract}

Keywords: College, autism, autistic spectrum disorders, asperger syndrome, phenomenological, qualitative

\section{Introduction}

The Diagnostic and Statistical Manual for Mental Disorders, $5^{\text {th }}$ edition (DSM-5) describes autistic spectrum disorder (ASD) as a mental health disorder stemming from a dyad of impairment; the social/communication difficulties and the repetitive behaviors/restricted interests [1]. Currently, nearly 1 in 50 children under 18 have been diagnosed with an ASD [2]. Of those, over $60 \%$ have a normal or higher IQ [3].

One of the key diagnostic features for ASD, restricted interests, appears in $88.5 \%$ of individuals with high functioning autism [4]. The autistic community refers to these as special interests and researchers have begun to consider these special interests as a strength for individuals with ASD $[5,6]$. As the name implies, individuals with ASD have intense interest in one topic or a restricted range of topics, yet these areas of focus form part of the self-identity of individuals with ASD. These interests can be utilized as a strength in both academic settings and their personal lives [7].

The number of people with an autistic spectrum disorder who attend college has grown along with the rate of ASD diagnoses $[3,8,9]$. Research has demonstrated that intelligence is the key difference between high and low functioning individuals with ASD [8] and that autistic impairments lessen as the individual ages $[10,11]$. Currently, over $40 \%$ of individuals with an ASD enroll in college $[9,11]$. However, they graduate college at lower rates than their normally developed peers $[\mathbf{9}, \mathbf{1 2}]$.

Positive life outcomes for individuals with ASD have been statistically correlated with success in obtaining a college degree $[\mathbf{9}, \mathbf{1 3}]$. Currently, colleges and universities lack autistic specific accommodations and generally give students with ASD accommodations meant for other impairments [14]. Based on the literature review, social scientists have not researched the phenomenon of college students with ASD in the depth required to develop effective supports at the college level.

Few studies have been done on college students with ASD. The academic literature focuses on the experiences of high school students with an ASD and apply those lessons to the college environment. Professionals recommend helping college student with ASD develop social skills, organization skills, and self-advocacy skills [15]. Wenzel and Rowley described a college seminar for incoming freshman with ASD based on these recommendations but did have data on success rates [16]. MacLeod and Green described lessons learned from a pilot program to support students with ASD. Their key lessons were that support programs needed to be proactive and engaged with the students [17].

Geller and Greenberg offered an expanded list of recommendations based on their experience with high school students with an ASD. They describe a need for additional training and support in social skills, asking for help, organizing, personal 
Sara Drake, Journal of Autism 2014,

appearance, and practical management. They also recommended making plans which included career goals, maximizing independence, and when supports could be phased out [18]. Whereas, VanBergeijik, Kiln, and Volkmar recommend assisting transitioning students to find the best fit between student and college [19].

Madriaga found college students with ASD had difficulty with the public spaces on campus and preferred quieter, solitary spaces. These preferences shaped their college experience. Those students with ASD who found access to solitary spaces indicating greater enjoyment of higher education [20]. Yet, other college students showed an openness to college students with autism. Nevill and White studied the reactions and impressions of college students to individuals with autism on campus. Openness to college students with ASD varied by academic major. Engineering majors had the highest comfort level with students with ASD, physical science majors had the highest willingness to spend time with college students with autism, and social science majors scored highest in willingness to live near a student with autism [21].

The data for this report came from a larger qualitative study using phenomenological methods to explore both the meaning individuals with ASD attribute to their experiences of academic success and their lived college experiences. In this article, the researcher describes the findings relating to the research question regarding the lived college experiences of individuals with an ASD.

\section{Methods}

\section{Participants}

This study included five participants; four women and one man. They had all completed a bachelor degree and two had completed a master degree. All five had been married in adulthood and four were married at the time of the interviews. Four of the participants had children. Three of the participants had formal diagnoses of ASD and two were self-diagnosed. Other demographic information was not collected.

Homogenous sampling was used for this study. Two criteria were used for the selection criteria (a) the individual identified themselves as having an autistic spectrum disorder and (b) they had a Bachelor's degree. Following the example of Brownlow, the researcher accepted self-diagnosed individuals as participants because the stigma attached to autism makes it unlikely an individual would claim to have the diagnosis without the symptoms [22]. The study continued until saturation, which was reached with five participants. The data was all collected using email. No incentives were offered. This study met with Walden University IRB approval.

\section{Materials and procedures}

This study was a phenomenological study using interpretative phenomenological analysis (IPA). Semi-structured interviewing was used to collect data. Interviews were conducted using email. The researcher emailed the participants one question at a time, allowing a dialogue to develop similar to a face-to-face interview. The researcher chose this form of communication because individuals with ASD prefer electronic or written communication as it allows them to compensate for some of their social and communication impairments [23].

The researcher completed the data analysis by using interpretive phenomenological analysis [24]. Each interview was analyzed separately. The researcher developed emerging themes and then analyzed the themes to develop superordinate themes. Once the interviews had been analyzed individually, the researcher analyzed the pattern of themes and super-ordinate themes across all participants. Lastly, the researcher interpreted the data through theoretical lens of neurodiversity theory [25] and the social model of disability [26].

\section{Results}

The participants discussed three superordinate themes: becoming self-aware, love of college, and finding alternate means to socialize. In addition to these superordinate themes, the participants indicated the value to their life of having attended college. For most, completing a degree opened employments options for the participants.

For some, it led to a career as G.H. described "'"'accounting is in generally stable demand, and I was looking for a profession that had portable skills and would pay the bills, and so far it's done a fine job of both". For other participants, having a college degree allowed them to maintain employment. E.F. described "Having a college degree does open a lot more job opportunities. I am grateful I have a degree - every job I've had has required 'a degree'". Even in indirect ways, the participants found having a college degree useful. I.J. wrote:

My wife tells me that one of the reasons she decided to marry me was because I had such a stable job; she had dated a large number of guys who weren't holding down such jobs; so my BS degree indirectly helped me get married, and that's added enormously to my life.

\section{Becoming self-aware}

The participants used their time in college to discover their own strengths and weaknesses. They used this self-awareness to make decisions regarding their majors, their career choices, and other life choices. For example A.B. wrote:

I took a step back and asked myself what I could do in the sciences with the math I already had successfully completed AND that would keep my interest with enough diversity that I wouldn't feel "hemmed in" or too narrowly specialized. The participants also developed self-awareness of their own capabilities. E.F. started college as a chemistry major but switched to English when she realized that's where her skills lay. She felt that she lacked the guidance she desired during college but discovered how to decide for herself. She wrote:

I think I really learned independence, I learned how to organize my own time and make my own decisions. I had always been very influenced by what my family thought I 
should do, and I really started to break away from that in college, making my decisions based on my own wants and needs. I.J. also found college helped him understand himself. He wrote that "another benefit was the UW taught me to think for myself. That has been invaluable for me". He summed up the need for self-awareness writing, "I made it through a lot of difficult classes; I learned that regardless of the difficulties I could find a way to overcome them if I worked hard enough". C.D. also found that what she learned about herself in college applied to the rest of her life, she wrote "my college life was very hard but maybe it helped prepare me for the rest of my life which has also been very hard and continues to be so".

\section{Love of college}

The participants found both a love of learning and a love of campus during their time in college. Even when the participants had a difficult time with other areas of college, a love of learning stood out as one of the best parts. C.D. wrote "the best parts were probably the few classes i really enjoyed (mostly literature)".

The participants discovered their love of learning in college. G.H. wrote that college "showed me, to my surprise, that I had an active mind and liked to learn new things". A.B. expanded on that concept; she wrote that she had found a "love knowledge for knowledge's sake". The love of learning extended beyond the individuals special interests, as G.H. explained "I also learned that I was fascinated by a wide variety of topics".

The physical environment on campus also mattered to the participants. G.H. described "walking across campus in the summer" as one of her favorite aspects of college. Additionally, the participants looked back on their time on campus with nostalgia. A.B. wrote "I really do miss being on campus". E.F. wrote "I really felt comfortable in that college world and love going back to visit the campus when I can".

\section{Finding alternate means to socialize}

College offered opportunities to build social connections for three of the participants. The relationships described by four of the participants as close friendships used terminology most often considered distant. For example, A.B. wrote "I still maintain close contact with high school, middle school, and a few college friends. One Army buddy. Unfortunately, none of them are even in the same state as me. Facebook is a wonderful thing though".

The participants described how they found ways to socialize through a variety of strategies. For E.F., she found a place for herself among other students generally considered outsiders on her campus. She wrote "my social life also blossomed in college as I was welcomed into a co-ed fraternity that was pretty much a group of geeks, misfits, and outcasts". G.H. found a sense of community through being a part of something larger, as she wrote "being part of something bigger than me (an ocean of students)".

E.F. wrote "Being able to go to 'my space' really reduced stress". She described the stress of living with others, writing "I had to room with someone who NEVER LEFT THE ROOM! Drove me crazy. Never got time to myself". Other participants expressed the importance of having their own space, particularly the "opportunity to live on my own" as I.J. described it.

C.D. warned of the dangers of trying normal socialization. She wrote "due to poor interpersonal skills I got taken advantage of got pregnant and dumped".

\section{Discussion}

This study has a few limitations. With only five participants, the sample size of this study was smaller than most qualitative studies limiting the transferability of the study results. Additionally, none of the participants had received an autism diagnosis before or during their time in college. They attended college prior to the release of the DSM-IV with its broader diagnostic criteria [27] and were not diagnosed under DSM-III criteria. Thus, these results do not include the effects of labelling. Further studies into the experiences of individuals with ASD in college would help expand on the findings from this study.

The noted preference for living alone during college supports Neville and White's study indicating college students with autism desire solitary spaces [21]. One practical implication arises from this; colleges could offer students with autism their own dorm room and accommodate this need for their own space.

The superordinate theme of becoming self-aware has broad implications for support services. Based on the literature review, the focus of support has been on teaching skills $[15,17]$. However, the participants found becoming self-aware more important than developing skills in their successful college experience. Further studies should look into methods support providers can use to encourage the development of selfawareness and the ability to think for themselves.

The participants' discussion of their love of college and learning offers a new view on the excepted ideas regarding restricted interests. Multiple participants discussed finding an enjoyment of learning in general as a result of taking college courses. It might be that the deeper look at particular topic typical of a college course appeals to individuals with ASD more than the what they found in high school courses.

Lastly, the participants' creative ways of finding social outlets that met their skillset and individual needs suggests strategies social service personnel can use to help individuals with ASD. It may be that exploring diverse social strategies may be as important as developing social skills.

\section{Conclusions}

College students with autism have the potential to succeed in an academic environment. The insights provided by those who have completed their degrees offer options for a way forward for psychologists and institutions interested in helping college students with autism succeed. 
Sara Drake, Journal of Autism 2014,

http://www.hoajonline.com/journals/pdf/2054-992X-1-5.pdf

List of abbreviations

ASD: Autistic Spectrum Disorder

Competing interests

The author declares that he has no competing interests.

Acknowledgement

Dr. Carlos Valdez served as the chairman of this study's

dissertation committee and Dr. Michael Johnson

served as the methods committee member.

Publication history

Editor: Larry Jarrett Barnhill, University of North Carolina at Chapel Hill, USA.

Received: 16-Sep-2014 Final Revised: 25-Oct-2014

Accepted: 28-Oct-2014 Published: 01-Nov-2014

\section{References}

1. American Psychiatric Association. Diagnostic and statistical manual of mental disorders (5 $5^{\text {th }}$ Ed). 2013; 50-55.

2. Blumberg SJ, Bramlett MD, Kogan MD, Schieve LA, Jones JR and Lu MC. Changes in prevalence of parent-reported autism spectrum disorder in school-aged U.S. children: 2007 to 2011-2012. Natl Health Stat Report. 2013; 65:1-11. | PubMed

3. Centers for Disease Control and Prevention. Community report from the Autism and Developmental Disabilities Monitoring (ADDM) network: Prevalence of Autism Spectrum Disorders (ASDs) among multiple areas of the United States in 2008. 2012. I Website

4. Klin A, Danovitch J. H, Merz A.B and Volkmar F.R. Circumscribed interests in higher functioning individuals with autism spectrum disorders: An exploratory study. Research \& Practice for Persons with Severe Disabilities. 2007; 32:89-100. I Pdf

5. Jordan CJ and Caldwell-Harris CL. Understanding differences in neurotypical and autism spectrum special interests through Internet forums. Intellect Dev Disabil. 2012; 50:391-402. I Article I PubMed

6. Winter-Messiers M.A. From tarantulas to toilet brushes: Understanding the special interest areas of children and youth With Asperger syndrome. Remedial and Special Education. 2007; 28:140-152. | Article

7. Winter-Messiers M.A, Herr C.M, Wood C.E, Brooks A. P, Gates M.A.M, Houston T.L. and Tingstad K.I. How far can Brian ride Daylight 4449 Express? A strength-based model of Asperger syndrome based on special interest areas. Focus on Autism and Other Developmental Disabilities. 2007; 22:67-79. | Article

8. Eaves LC, Ho HH and Eaves DM. Subtypes of autism by cluster analysis. $J$ Autism Dev Disord. 1994; 24:3-22. I Article I PubMed

9. Newman L, Wagner M, Knokey A.-M, Marder C, Nagle K, Shaver D and Schwarting $M$. The post-high school outcomes of young adults with disabilities up to 8 Years after high school. A report from the National Longitudinal Transition Study-2 (NLTS2) (NCSER 2011-3005). 2011. | Article

10. Seltzer MM, Krauss MW, Shattuck PT, Orsmond G, Swe A and Lord C. The symptoms of autism spectrum disorders in adolescence and adulthood. J Autism Dev Disord. 2003; 33:565-81. | Article | PubMed

11. Taylor JL and Seltzer MM. Changes in the autism behavioral phenotype during the transition to adulthood. J Autism Dev Disord. 2010; 40:143146. | Article | PubMed Abstract | PubMed Full Text

12. National Center for Educational Statistics. Postsecondary graduation rates (indicator 45-2012). 2012.

13. Socha T, Cataldi E.F, Green C, Henke R, Terry L, Woo J and Siegel P. 200809 Baccalaureate and beyond longitudinal study (B\&B:08/09) First look. National Center for Educational Statistics, U.S. Department of Education. 2011. I Pdf

14. Smith C. P. Support services for students with Asperger's syndrome in higher education. College Student Journal. 2007; 41:515-531. I Article

15. Ciccantelli L.A. College navigation for students with autism spectrum disorder: The need for advanced preparation. Global Education Journal. 2011; 2:53-63. | Article

16. Wenzel $C$ and Rowley L. Teaching social skills and academic strategies to college students with Asperger's syndrome. Teaching Exceptional Children. 2010; 42:44-50. | Article

17. MacLeod A and Green S. Beyond the books: case study of a collaborative and holistic support model for university students with Asperger syndrome. Studies in Higher Education. 2009; 34:631-646. | Article

18. Geller L.L and Greenberg M. Managing the transition process from high school to college and beyond: Challenges for individuals, families, and society. Social Work in Mental Health. 2010; 8:92-116. I Article

19. Vanbergeijk E, Klin A and Volkmar F. Supporting more able students on the autism spectrum: college and beyond. J Autism Dev Disord. 2008; 38:1359-70. | Article I PubMed

20. Madriaga M. 'I avoid pubs and the student union like the plague': Students with Asperger syndrome and their negotiation of university spaces. Children's Geographies. 2010; 8:39-50. I Article

21. Nevill RE and White SW. College students' openness toward autism spectrum disorders: improving peer acceptance. J Autism Dev Disord. 2011; 41:1619-28. | Article | PubMed

22. Brownlow C. Presenting the self: negotiating a label of autism. J Intellect Dev Disabil. 2010; 35:14-21. | Article | PubMed

23. Robertson S.M and Ne'eman A.D. Autistic acceptance, the college campus, and technology: Growth of neurodiversity in society and academia. Disability Studies Quarterly. 2008; 28:14. I Article

24. Smith J.A, Flowers $P$ and Larkin $M$. Interpretative phenomenological analysis: Theory, method and research. 2009.

25. Boundy K. "'Are you sure, sweetheart, that you want to be well?'": An exploration of the neurodiversity movement. Radical Psychology: $A$ Journal of Psychology, Politics \& Radicalism. 2008; 7:2. I Article

26. Oliver M. The politics of disablement. 1990.

27. American Psychiatric Association. Diagnostic and statistical manual of mental disorders (4 $\left.{ }^{\text {th }} \mathrm{Ed}\right) .2000$.

Citation:

Drake S. College experience of academically successful students with autism. J Autism. 2014; 1:5. http://dx.doi.org/10.7243/2054-992X-1-5 